\title{
ARBITRAJE OBLIGATORIO Y DE DERECHO EN LA CONTRATACIÓN PÚBLICA
}

\author{
Mario Castillo Freyre* \\ Rita SABROSO MinayA*
}

\begin{abstract}
Resumen
La cláusula obligatoria de arbitraje, frente a las discrepancias que surjan en la ejecución o interpretación de los contratos de adquisiciones y contrataciones del Estado, ha significado un cambio trascendental para la administración pública, no solo peruana, sino de toda América Latina. Esto demuestra y destaca la eficacia de la vía arbitral como medio alternativo de solución de conflictos, disminuyendo tiempo, costos y riesgos en las relaciones contractuales entre Estado y los particulares, asegurando de este modo la inversión nacional y extranjera.
\end{abstract}

En esta línea de ideas, si bien el arbitraje es de aplicación obligatoria e irrenunciable, ello no significa negar la naturaleza consensual del mismo, lo que además marca una diferencia sustancial con la Ley General de Arbitraje, en la cual sí es posible que a pesar del convenio arbitral, las partes acuerden recurrir al Poder Judicial, por lo que nos encontraremos frente a un arbitraje de pleno derecho en la contratación pública.

Palabras clave: Arbitraje - Contrataciones del Estado.

\begin{abstract}
Application of a mandatory arbitration clause, when differences arise as to the performance or construction of government acquisition and procurement agreements, has represented a momentous change for the public administration, not only in Peru, but in Latin America as a whole. This evidences and emphasizes the efficiency of the arbitrary channel as an alternative conflict solving mean, reducing time, costs and risks in contract relationships between the Government and individuals, thus guaranteeing national and foreign investment.

In this order of ideas, although arbitration is applied mandatorily and compulsorily, it does not deny its consensual nature. It also establishes a considerable difference with the General Arbitration Act, which, despite the existence of an arbitration agreement, enables the parties to agree to resort to the Judiciary. So, we have an ipso jure arbitration in public procurement.
\end{abstract}

Key words: Arbitration - Government Procurement.

\footnotetext{
* Profesor principal de Obligaciones y Contratos en la Pontificia Universidad Católica del Perú y en la Universidad Femenina del Sagrado Corazón.

* Adjunta de Docencia de Derecho de las Obligaciones en la Facultad de Derecho de la Pontificia Universidad Católica del Perú.
} 


\section{Sumario}

1. Introducción. 2. ¿Arbitraje obligatorio? 3. Arbitraje de derecho en la contratación pública.

\section{INTRODUCCIÓN}

El tercer párrafo del artículo $63^{\circ}$ de la Constitución Política del Perú establece que "el Estado y las demás personas de derecho público pueden someter las controversias derivadas de relación contractual (sic) [...] a arbitraje nacional o internacional, en la forma en que lo disponga la ley". Esta referencia constitucional a una ley, nos lleva a la nueva Ley de Arbitraje, Decreto Legislativo $N^{\circ} 1071$ (en adelante, Ley de Arbitraje), cuyo artículo 4ㄹ, inciso 2 , establece que "las controversias derivadas de los contratos y convenios celebrados entre estas entidades estatales pueden someterse también a arbitraje nacional", mientras que el inciso 3 señala claramente que "el Estado puede someter a arbitraje nacional las controversias derivadas de los contratos que celebre con nacionales o extranjeros no domiciliados en el país".

Como se puede apreciar, en la Ley de Arbitraje, el Estado y sus entidades están considerados en un plano de igualdad con las partes en virtud de un convenio arbitral.

Cabe recordar que uno de los aspectos que revolucionó la administración de justicia en el país fue la disposición contenida en el artículo $41^{\circ}$ de la antigua Ley de Contrataciones y Adquisiciones del Estado, Ley N² 26850 del año 19981, que estableció - por primera vez - como una de las cláusulas obligatorias en los contratos de adquisiciones y contrataciones, la de solución de controversias, estableciendo que "cuando en la ejecución o interpretación del contrato surja entre las partes una discrepancia, esta será definida mediante el procedimiento de conciliación extrajudicial o arbitraje, según lo acuerden las partes" ${ }^{2}$.

Las posteriores leyes y reglamentos (Decreto Supremo $N^{\circ}$ 012-2001-PCM, Decreto Supremo Nº13-2001-PCM, Decreto Supremo N 083-2004-PCM, Decreto Supremo N 084-2004-PCM, Decreto Legislativo No 1017 y Decreto Supremo $\mathrm{N}^{\circ}$ 184-2008-EF) han mantenido la regla de incluir la cláusula obligatoria de solución de controversias.

En efecto, como hemos venido sosteniendo a lo largo de los últimos años, estas disposiciones transformaron radicalmente la administración de justicia 
en el Perú, en la medida en que introdujeron a la conciliación y al arbitraje obligatorios como mecanismos de solución de controversias en todos los conflictos suscitados en los contratos que el Estado celebra con particulares, ya sea con respecto a la adquisición de bienes y servicios o con respecto a la ejecución de obras y a su supervisión.

Se trata de una situación especial en el contexto de América Latina, porque no solo se implantó el arbitraje obligatorio, sino que, además, ello significó que el Estado peruano era consciente de que no necesariamente el propio Estado resultaba ser el más indicado para administrar justicia en sus propios conflictos.

Esto implica, evidentemente, que se asumió que la vía arbitral era más adecuada que la propia justicia ordinaria para solucionar estas diferencias, dada la duración excesiva de los procesos judiciales relativos a este tema ${ }^{3}$.

Como bien señala Bullard", las características de nuestro Poder Judicial condujeron a la creación de una serie de "sustitutos" confiables. Dado que la reforma del Poder Judicial parece tan difícil y toma tanto tiempo, las privatizaciones parecen no poder esperar. Había que crear mecanismos alternativos para generar confianza. Así, se renuncia o se difieren las reformas judiciales, y se pone énfasis en la creación de diversos mecanismos destinados a limitar las prestaciones del sistema político sobre los agentes económicos.

El esquema que se implantó con la Ley $N^{\circ} 26850$ ha tenido éxito en la medida en que ha sido mantenido con las mismas características en los últimos gobiernos que han regido en el Perú. No olvidemos que esta norma es del penúltimo gobierno de Fujimori y se mantuvo en su último gobierno, durante el gobierno del Presidente Paniagua, en el gobierno del Presidente Toledo y en el actual gobierno.

Ello ha dado muy buenos resultados en la medida en que la solución de estas controversias ha demostrado a la sociedad que el medio arbitral es - por lo general - más eficiente que la justicia ordinaria, disminuyendo tiempo y costos en la administración de justicia. Así, tanto las entidades públicas como las empresas contratistas se encuentran satisfechas con la implantación de este mecanismo de solución de controversias.

Cantuarias $^{5}$ señala que si el Estado peruano no arbitrara las controversias generadas en el campo comercial, lo más probable es que tendría pocos 
ofertantes de los bienes y servicios que consume (solo participarían aquellos que tienen menos aversión al riesgo de someterse al Poder Judicial peruano) y a mayores precios (ya que el riesgo de someterse a una instancia poco neutral como es el Poder Judicial del Estado interviniente en la operación, necesariamente afectará las condiciones del intercambio).

Tal consideración podría tener algo de verdad; sin embargo, dudamos mucho de que la mayor o menor participación de empresas interesadas en contratar con el Estado obedezca al arbitraje como medio de solución de controversias. No hay mucho que escoger cuando el mayor adquirente de bienes y servicios, el propio Estado, quiere contratar con uno.

Además, hay que señalar que a través de esta vía se ha producido una verdadera transformación en la administración de justicia, en la medida en que, como todos sabemos, es muy grande la cantidad de procesos arbitrales que se derivan de los conflictos relacionados con contratos que celebran los particulares con el Estado y sus entidades. Asimismo, los montos en controversia son bastante altos. Los arbitrajes en donde - por lo menos - una de las partes es el Estado, representan alrededor del 70\% del total de procesos arbitrales que están en curso en nuestro país.

Y, por otro lado, estas cláusulas obligatorias han contribuido a que las controversias sobre cuantías muy altas, hoy estén sustraídas del Poder Judicial. Ello, aunado al hecho de que en la mayoría de contratos entre particulares (en donde se comprometen montos patrimoniales importantes), se incluye una cláusula arbitral y, por lo tanto, también se sustraen las partes de los tribunales ordinarios.

Si bien el Estado tiene que generar confianza en aquellos que vayan a contratar con él, asegurándoles que de surgir algún conflicto, este se solucionará de manera imparcial, pronta y adecuada, hay quienes afirman ${ }^{6}$ que ello no implicaba inexorablemente que el conflicto no sea resuelto por el Poder Judicial, sino que el Estado debía proveer de un Poder Judicial autónomo e independiente, de jueces capacitados, a quienes se les respete la especialización en determinadas materias, y se les otorgue una carga procesal razonable que les permita resolver de manera pronta. En síntesis, es imprescindible realizar una verdadera y comprometida reforma, lo que indudablemente tiene un costo importante en tiempo, esfuerzo y dinero. Sin embargo, el Estado ha optado por lo urgente y lo inmediato, admitiendo que el arbitraje constituye, decididamente, un mecanismo más confiable que el jurisdiccional. 
En efecto, dadas las especiales características del arbitraje y sobre todo su celeridad, no cabe duda de que se ha convertido en el mecanismo que - actualmente - brinda mayores ventajas a los particulares e, incluso, al propio Estado.

\section{2. ¿ARBITRAJE OBLIGATORIO?}

Como sabemos, el artículo $40^{\circ}$ del Decreto Legislativo $N^{\circ}$ 1017, Ley de Contrataciones y Adquisiciones del Estado (en adelante, Ley de Contrataciones y Adquisiciones del Estado) ${ }^{7}$, establece que los contratos regulados por dicha norma incluirán necesariamente y bajo responsabilidad, cláusulas referidas, entre otras, a la solución de controversias. En efecto, el referido artículo $40^{\circ}$ establece lo siguiente:

“Artículo $40^{\circ}$.- Cláusulas obligatorias en los contratos

Los contratos regulados por la presente norma incluirán necesariamente y bajo responsabilidad cláusulas referidas a:

[...]

c) Solución de Controversias: toda controversia surgida durante la etapa de ejecución del contrato deberá resolverse mediante conciliación o arbitraje. En caso que en las bases o el contrato no se incluya la cláusula correspondiente, se entenderá incorporada de pleno derecho la cláusula modelo que establezca el Reglamento.

$[\ldots]^{\prime \prime}$.

En ese sentido, el primer rasgo característico importante a resaltar en esta materia, es que se trataría de un arbitraje obligatorio ${ }^{8}$, cuya cláusula arbitral no es negociable por las partes.

En efecto, debemos recordar que una posible clasificación del arbitraje es por su fuente; a saber: arbitraje voluntario y arbitraje forzoso u obligatorio.

Es voluntario cuando son las partes en conflicto - actual o potencial - las que deciden someter la decisión a un tercero neutral. Esto hace la esencia del arbitraje, ya que parte de una manifestación de confianza y de un reconocimiento tanto de la capacidad y pericia del árbitro, cuanto de su sentido de equidad. Por su parte, el arbitraje es forzoso cuando viene impuesto por voluntad del legislador, quien manda que determinados conflictos sean resueltos mediante arbitraje ${ }^{9}$.

Ahora bien, la figura tradicional del arbitraje o del convenio arbitral implica que este sea pactado voluntariamente por las partes, ya que la autonomía de la 
voluntad de las partes constituye la esencia y el fundamento de la institución arbitral.

En efecto, el ingreso a la jurisdicción arbitral requiere de la aceptación expresa de las partes. Ello no implica que el convenio arbitral contenga todos los aspectos que regirán el arbitraje, puesto que, en defecto de mayor detalle, se aplicarán las reglas establecidas en la Ley de Arbitraje. En ese sentido, una cláusula arbitral simple que contenga el acuerdo de las partes de recurrir al arbitraje, bastará para habilitar la vía arbitral, porque las partes así lo han querido.

Como bien señala García-Calderón ${ }^{10}$, esta autonomía de la voluntad está mencionada en la Ley General de Arbitraje ${ }^{11}$ y lo estuvo también en el Código Civil de 1984, y fue así históricamente desde sus orígenes en el Perú, es decir, desde el Código de Enjuiciamientos Civiles de 1851, siendo esta la primera norma peruana que precisaba la consensualidad para someter la controversia a una solución privada o alternativa al Poder Judicial.

A entender de Baca ${ }^{12}$, el carácter voluntario del arbitraje parece excluir, por definición, la posibilidad de que este sea impuesto obligatoriamente. Es decir, una ley no podría establecer como obligatorio el sometimiento a arbitraje de determinados conflictos, excluyendo así su control judicial (salvo los tasados supuestos del recurso de anulación contra los laudos), pues esto sería contrario al derecho a la tutela judicial efectiva ${ }^{13}$.

Por el contrario, en el caso de las contrataciones públicas, el arbitraje es una imposición de la propia ley y su inclusión en todo contrato que celebre el Estado para proveerse de bienes, servicios, obras o supervisión de las mismas, es obligatoria ${ }^{14}$.

Sobre este tema, Kundmüller ${ }^{15}$ nos dice que en el caso de las contrataciones y adquisiciones del Estado, las vías de arbitraje y conciliación han quedado establecidas legalmente como necesarias para la solución de controversias sobrevinientes en la etapa de ejecución de los contratos, sustituyendo o excluyendo a las vías administrativa y judicial.

$\mathrm{Al}$ respecto, Arrarte y Paniagua ${ }^{16}$, se cuestionan por qué en nuestro ordenamiento jurídico, se ha establecido con carácter obligatorio que las controversias derivadas de la ejecución de contratos con el Estado sean resueltas a través de un arbitraje, sin que quepa la posibilidad de que esta función pueda ser realizada por los órganos jurisdiccionales, vía originaria prevista en la Constitución Política del Perú. 
A entender de los citados autores, lo indicado tiene mayor sentido, si consideramos que detrás de la solución de conflictos derivados de la ejecución de un contrato con el Estado, se encuentra la realización de un interés eminentemente público, mientras que en el arbitraje, el carácter privado y particular constituye su esencia, su razón de ser.

Por su parte, Trayter ${ }^{17}$ afirma que no estamos en presencia de auténticos arbitrajes cuando la única vía, impuesta legalmente, es la del sometimiento a la decisión de unas personas denominadas árbitros.

Así, para Arrarte y Paniagua ${ }^{18}$, lo previsto en nuestra legislación, es un mandato imperativo e irrenunciable, en donde no existe la posibilidad de utilizar la vía judicial, en tanto expresamente se ha excluido esta posibilidad, lo cual implica que, contrariamente a lo que ocurre en cualquier convenio arbitral, si alguna de las partes, sea el Estado o un particular, recurre a un órgano jurisdiccional, este debe declararse incompetente - incluso de oficio - para conocer cualquier controversia derivada de un contrato celebrado por el Estado, sin que quepa la posibilidad de que como producto de un acuerdo entre las partes, le otorguen competencia para emitir un pronunciamiento válido.

Para salvar esta severa incompatibilidad, tal como la catalogan Arrarte y Paniagua, hay quienes sostienen que el mandato de la Ley de Contrataciones y Adquisiciones del Estado es una autoexigencia para el Estado, el mismo que debe incorporar la cláusula arbitral en sus contratos, sin que ello implique afectación a la voluntariedad del arbitraje.

En efecto, a entender de Cuevas ${ }^{19}$, si bien se establece que el arbitraje es de aplicación obligatoria, ello no significa negar el carácter consensual del arbitraje. Lo que ocurre es que una de las partes, en este caso la entidad correspondiente del Estado, incluye -o, mejor dicho, debe incluir - un convenio arbitral dentro de los contratos que celebre con sus proveedores, el mismo que es aceptado por estos al participar en la respectiva convocatoria pública. Es más, dicho convenio es expresamente aceptado por el proveedor al suscribir el contrato con el Estado. En consecuencia, la obligatoriedad a la que alude la Ley de Contrataciones y Adquisiciones del Estado está referida a la obligación que tiene el Estado de incorporar en sus contratos el arbitraje, como la forma de resolver sus controversias con sus proveedores.

Sobre el particular, Santistevan de Noriega ${ }^{20}$ se resiste al concepto de arbitraje obligatorio y prefiere admitir la doctrina de las condiciones generales de contratación, bajo la fórmula de que el Estado lo que hace, en la contratación 
regida por los términos de la Ley de Contrataciones y Adquisiciones del Estado, es extender una oferta general de arbitraje, que el contratante acoge al celebrar el contrato o a la que se adhiere.

Asimismo, el citado autor sostiene que se puede admitir que el Estado (que no obliga a nadie a contratar con sus dependencias) lo que hace es adelantar por ley su voluntad de arbitrar, es decir, incluirla como una oferta incorporada en una cláusula general a la que debe someterse todo aquel particular que quiera contratar bajo este régimen. Dicho autor prefiere asimilar este caso a una modalidad de contratación por adhesión.

Al respecto, Kundmüller ${ }^{21}$ señala que es de público conocimiento para los futuros contratantes con el Estado, la existencia de esta cláusula obligatoria. De ahí que todo aquel que contrate o que tenga intención de contratar con el Estado y sea un mínimo diligente, sabe de la preexistencia de dicha cláusula obligatoria y está en libertad de participar o no en los procedimientos de contratación.

El referido autor concluye en que hay innegables similitudes entre la figura del derecho privado de los convenios arbitrales estándares, previstos en la Ley General de Arbitraje y las estipulaciones obligatorias contenidas en los contratos regulados en la legislación de contrataciones y adquisiciones del Estado, en el marco del derecho público.

A entender nuestro, existe una diferencia importante entre lo previsto en la Ley de Contrataciones y Adquisiciones del Estado y lo regulado en la Ley de Arbitraje en relación a las cláusulas generales estándares, ya que en este último caso, es posible que a pesar del convenio arbitral contemplado en las cláusulas generales las partes acuerden recurrir al Poder Judicial, lo que obviamente no puede suceder en la contratación pública.

Por otro lado, encontramos a Cantuarias ${ }^{22}$, quien nos dice que el arbitraje regulado por la Ley de Contrataciones y Adquisiciones del Estado ${ }^{23}$ no tiene nada de obligatorio, ya que el Estado al momento de ofertar las adquisiciones de bienes y servicios está en plena libertad de proponer el acceso al arbitraje como parte de sus condiciones. Si algún particular libremente desea contratar con el Estado, pues tendrá que someterse a las condiciones de la oferta, una de las cuales será el acceso al arbitraje.

Si bien para el citado autor no estamos frente a un arbitraje obligatorio, pone de manifiesto que sí es inconveniente que el Estado no pueda ofertar a los particulares otras vías adicionales de solución de conflictos. 
Finalmente, García-Calderón ${ }^{24}$ sostiene que esta obligatoriedad del arbitraje es una figura atípica, ya que se trata de una obligación para el Estado (empresas del Estado de derecho público o privado, sean gobiernos locales, gobiernos regionales o gobierno central), quien debe, obligatoriamente, al convocar a una licitación pública, establecer que en el contrato futuro se consignará una cláusula arbitral, por lo que todo aquel que contrate con el Estado debe aceptar dicha condición, en la medida en que quiera celebrar un contrato con el gobierno central, gobierno regional o gobiernos locales.

A entender del citado autor, es una obligación que, sin duda, respeta la naturaleza jurídica del arbitraje, ya que se trata de una autoimposición para las empresas estatales; estamos en presencia de una exigencia interna, tal como lo señala el artículo $41^{\circ}$ de la Ley al incluir cláusulas obligatorias en los contratos, bajo responsabilidad del titular del pliego o de los responsables. Esta exigencia no atenta contra la autonomía de la voluntad de las partes.

Así, García-Calderón señala que esta sutil diferencia jurídica es de suma importancia, ya que la ley no obliga a un tercero a someterse al arbitraje cuando este no lo desea. Si la ley dijese, por ejemplo, que en todos los casos en materia de arrendamiento se deberá acudir al arbitraje y no al Poder Judicial, entonces sí se trataría de una imposición forzosa o legal (no voluntaria), y vulneraría la esencia de la naturaleza jurídica del arbitraje, pero en el artículo bajo comentario nadie está obligado a contratar con el Estado.

Coincidimos con el citado autor en que es evidente que cualquiera que desee contratar con el Estado se verá afectado y deberá someterse a esta obligatoriedad, en la medida en que se desee contratar, dado que se trata de una exigencia interna de este, tal como puede ocurrir con cualquier empresa privada que exige requisitos mínimos para poder contratar con terceros. El Estado plasma sus políticas a través de normas jurídicas, y en este caso no atenta contra el derecho de terceros.

Otro aspecto importante a destacar es la inclusión de pleno derecho de un modelo de cláusula arbitral, en caso las partes no la hayan establecido.

Así, el artículo $216^{\circ}$ del Decreto Supremo No 184-2008-EF, Reglamento de la Ley de Contrataciones y Adquisiciones del Estado (en adelante, el Reglamento), establece que si el contrato no incorpora un convenio arbitral, se considerará incorporado de pleno derecho el siguiente texto, que remite a un arbitraje institucional del Sistema Nacional de Arbitraje del Organismo Supervisor de las Contrataciones del Estado (OSCE), cuya cláusula arbitral tipo es la siguiente: 


\begin{abstract}
“Todos los conflictos que deriven de la ejecución e interpretación del presente contrato, incluidos los que se refieran a su nulidad e invalidez, serán resueltos de manera definitiva e inapelable mediante arbitraje de derecho, de conformidad con lo establecido en la normativa de contrataciones del Estado, bajo la organización y administración de los órganos del Sistema Nacional de Arbitraje del OSCE y de acuerdo con su Reglamento".
\end{abstract}

Al respecto, García-Calderón ${ }^{25}$ tiene una posición muy interesante sobre la incorporación de pleno derecho de la cláusula arbitral, considerándola ilegal. Así, sostiene que si el convenio arbitral no consta en el contrato que han suscrito la dependencia u organismo estatal y el particular, no podrá invocarse el arbitraje, a pesar de que el reglamento contemple su incorporación de pleno derecho.

El citado autor discute sobre la obligatoriedad de la norma para aquellos particulares que contraten con el Estado y que no hayan suscrito el convenio arbitral, toda vez que la doctrina y la ley de arbitraje recogen el carácter voluntario (consensual) del arbitraje. Quiere decir entonces que si por un error administrativo no se incluyó el convenio arbitral en el contrato, no se puede incorporar el arbitraje sin el consentimiento de la otra parte, tal como equivocadamente lo señala el reglamento.

En tal sentido, para García-Calderón, la obligatoriedad del arbitraje de pleno derecho atenta contra la autonomía de la voluntad de las partes, contra los principios de legalidad y contra el debido proceso. De esta manera, el citado profesor entiende esta incorporación como una limitación ilegal por parte del Estado a la jurisdicción ordinaria, que no debe ser aceptada en caso se presente alguna controversia si no se ha suscrito el convenio arbitral.

Al respecto, debemos señalar que no compartimos esta posición en torno a la ilegalidad de la incorporación de pleno derecho del arbitraje, ya que aquí también debe tenerse en cuenta que la ley no obliga a contratar con el Estado y que, por ello, el particular que desea contratar con el Estado sabe que si no pacta cláusula arbitral alguna con la entidad, se entenderá incluida la cláusula arbitral tipo.

Como bien señala Kundmüller ${ }^{26}$, la obligatoriedad del arbitraje en la contratación pública podría estar justificada por una serie de circunstancias y razones basadas en nuestra realidad. Sin embargo, es necesario que las partes involucradas conozcan a cabalidad que dicha "obligatoriedad" existe y cuáles 
son sus consecuencias respecto del arbitraje, especialmente en lo relativo a las atribuciones del organismo supervisor de las contrataciones del Estado, en caso no se hayan sometido a las reglas de una institución administradora y en caso el contrato no incorporase un convenio arbitral.

A nuestro entender, el considerar incorporado - de pleno derecho - dicho convenio arbitral, permitirá garantizar la plena vigencia del arbitraje en las contrataciones con el Estado, aunque las partes no lo hubieran pactado formalmente en el contrato. Es decir, nos encontramos ante una cláusula arbitral que podríamos denominar como:

\section{ARBITRAJE DE DERECHO EN LA CONTRATACIÓN PÚBLICA}

En el arbitraje de derecho los árbitros deben resolver las controversias aplicando el ordenamiento jurídico, al igual que un juez. Por el contrario, en el arbitraje de conciencia, los árbitros no están sometidos a reglas en particular, ya que fallan de acuerdo a su leal saber y entender.

Si bien existen varias razones por las cuales las partes pueden preferir un arbitraje de conciencia a uno de derecho ${ }^{27}$, también existe el temor de que este tipo de arbitraje sea arbitrario, caprichoso o, cuando menos, demasiado subjetivo.

En efecto, existe el temor de que mediante un arbitraje de conciencia se pueda contravenir lo establecido por la ley.

Ciertamente no resulta lógico ni deseable socialmente que los particulares resuelvan sus problemas contra la ley. Por ello, toda vez que el arbitraje es un medio de solución de conflictos, dicha solución no debería pasar por pisotear la ley.

Algunos podrían argumentar con una interpretación extrema, que ello es posible si la misma ley así lo permite en el caso específico del arbitraje de conciencia. Esta parece ser la posición del profesor Álvaro Aliaga ${ }^{28}$, para quien los árbitros de conciencia se encargan de resolver la controversia obedeciendo a lo que su prudencia y equidad les dicten, por lo que no están obligados en sus procedimientos ni en sus laudos a lo establecido en otras reglas, sino únicamente a lo que las partes hayan determinado en el acuerdo arbitral.

No compartimos dicha posición, ya que - a entender nuestro - no resulta coherente que el ordenamiento jurídico dé carta blanca para su eventual violación a través del arbitraje de conciencia. 
Fernando De Trazegnies ${ }^{29}$ advirtió sobre la presencia del círculo vicioso en que incurre generalmente la doctrina. En efecto, el referido autor sostiene que caemos ante un perfecto razonamiento circular cuando se dice que el arbitraje de conciencia funciona conforme al leal saber y entender del árbitro, $\mathrm{y}$, a su vez, el leal saber y entender es guiado por la equidad; pero cuando preguntamos sobre lo que es la equidad, nos encontramos con la extraña respuesta de que es lo que según el leal saber y entender de los árbitros, estos consideran equitativo.

Una posición interesante es la de Guillermo Lohmann ${ }^{30}$, quien sostiene que los árbitros de conciencia se pronuncian según criterios extra-jurídicos, ya que el ordenamiento legal es dejado de lado por completo. Y, por tanto, es perfectamente posible que el laudo de conciencia sea contrario a ley. Sin embargo, dicho autor precisa que a través del arbitraje de conciencia se puede resolver dejando de lado las normas legales dispositivas aplicables al caso $\mathrm{y}$, asimismo, se pueden dejar de aplicar disposiciones contractuales que se consideren injustas, pero nunca dejar de lado las normas imperativas.

Recordemos que el inciso 3 del artículo $57^{\circ}$ de la Ley de Arbitraje contempla la posibilidad de que las partes pacten arbitraje de conciencia, al establecer que "en cualquiera de los supuestos previstos en los apartados 1 y 2 de este artículo, el tribunal arbitral decidirá en equidad o en conciencia, solo si las partes le han autorizado expresamente para ello".

Con esta modificación se está regresando a lo establecido en la primera Ley General de Arbitraje, en donde el arbitraje de derecho era la regla, mientras que el arbitraje de conciencia era la excepción. En efecto, el último párrafo del artículo $3^{\circ}$ del Decreto Ley $\mathrm{N}^{\circ} 25935^{31}$, establecía que a falta de pacto expreso, se presume que las partes optan por un arbitraje de derecho.

En su momento Cantuarias y Aramburú ${ }^{32}$ manifestaron su disconformidad con la antigua Ley General de Arbitraje, que consideraba como regla al arbitraje de derecho y solo como excepción al arbitraje de conciencia. La razón tenía que ver con el hecho de que el arbitraje de derecho constituye una función monopólica en manos de los abogados, a diferencia del arbitraje de equidad, donde sí pueden participar el resto de ciudadanos. Existiendo dicha situación, lo razonable - a entender de los citados autores - era que la actividad monopólica sea la excepción y no la regla.

En cambio, con la siguiente Ley General de Arbitraje, Ley N² 26572, se invirtió la relación entre el arbitraje de derecho y el de conciencia, siguiendo - de alguna manera - la observación anotada. 
Sin embargo, el inciso 4 del artículo $57^{\circ}$ de la actual Ley de Arbitraje tiene como objetivo no solo seguir la tendencia internacional, sino sobre todo la experiencia observada, que muestra que lo que se suele pactar es el arbitraje de derecho, es decir, que lo común es un pacto en contrario de la norma.

Al respecto, Zegarra Pinto $^{33}$ señala que a partir de la legislación comparada, la tendencia actual es considerar al arbitraje de derecho como la regla ${ }^{34}$.

Ahora bien, en materia de contratación pública, todas las legislaciones de nuestro país han contemplado al arbitraje de derecho como aquel que se aplicará para la solución de controversias. Ello, de seguro, porque el legislador ha querido y quiere evitar que - precisamente - el arbitraje sobre esta materia sea arbitrario o subjetivo.

Así, por ejemplo, si bien la Ley $\mathrm{N}^{\circ}$ 26850, antigua Ley de Contrataciones y Adquisiciones del Estado, no establecía expresamente que se trataba de un arbitraje de derecho, su Reglamento, el Decreto Supremo N 13-2001-PCM, sí lo hacía, al señalar lo siguiente:

"Artículo $186^{\circ}$.- Aplicación del Arbitraje.-

El arbitraje será de aplicación obligatoria en la solución de controversias surgidas después de la suscripción o cumplimiento de la formalidad de perfeccionamiento de los contratos derivados de los procesos de selección hasta el consentimiento de su liquidación. [...]

[...]

El arbitraje regulado en el presente Subcapítulo, en todos los casos, será de derecho" ${ }^{\prime \prime}$ (El subrayado es nuestro).

Por su parte, la siguiente Ley de Contrataciones y Adquisiciones del Estado, Decreto Supremo Nº83-2004-PCM, establecía:

"Artículo 53.- Solución de controversias.-

[...]

Las controversias que surjan entre las partes, desde la suscripción del contrato, sobre su ejecución, interpretación, resolución, inexistencia, ineficacia o invalidez, se resolverán mediante conciliación y/o arbitraje [...]

El arbitraje será de derecho $[\ldots]^{\prime \prime}$. (El subrayado es nuestro).

Por último, el segundo párrafo del artículo $52^{\circ}$ de la actual Ley de Contrataciones y Adquisiciones del Estado establece lo siguiente: 


\begin{abstract}
“Artículo 52.- Solución de controversias
[...]

El arbitraje será de derecho, a ser resuelto por árbitro único o tribunal arbitral mediante la aplicación del presente Decreto Legislativo y su Reglamento, así como de las normas de derecho público y las de derecho privado; manteniendo obligatoriamente este orden de preferencia en la aplicación del derecho". (El subrayado es nuestro).
\end{abstract}

A entender de Kundmüller ${ }^{35}$, el hecho de exigir que el arbitraje sea de derecho constituye una grave limitación a la libertad de las partes para determinar el tipo de arbitraje que convenga a sus intereses, significando también una gravísima limitación para la libre determinación de las partes respecto del modo apropiado de gestión de sus conflictos en sede arbitral.

Según el citado autor, en el caso de los temas regulados por el Reglamento y la Ley de Contrataciones y Adquisiciones del Estado esto cobra especial relevancia, ya que básicamente estamos hablando de asuntos que se refieren a temas de ingeniería o concernientes a otras especialidades no necesariamente del campo del derecho.

Dicha opinión no es compartida por García-Calderón ${ }^{36}$, quien considera que tratándose de los intereses del Estado, representados sea por una persona jurídica de derecho público o privado, no se debe dejar al libre albedrío o al criterio subjetivo de los árbitros de equidad la resolución del conflicto, sino que debe basarse en una interpretación jurídica y al amparo de una ley determinada y tomando en cuenta en su decisión la prueba que respalda el derecho invocado.

Ahora bien, el segundo párrafo del citado artículo $52^{\circ}$ de la Ley de Contrataciones y Adquisiciones del Estado no deja opción a elegir y dispone que en todos los casos el arbitraje sobre controversias relativas a la contratación pública será de derecho.

Conforme a lo establecido por el inciso 1 del artículo $22^{\circ}$ de la Ley de Arbitraje, "en el arbitraje nacional que deba decidirse en derecho, se requiere ser abogado, salvo acuerdo en contrario", con lo cual solo los abogados podrían arbitrar las referidas controversias. La salvedad establecida por el citado inciso 1 no estaría pactada por las partes, sino por la propia Ley de Contrataciones y Adquisiciones del Estado, cuyo artículo $52^{\circ}$ contempla la posibilidad de que los árbitros designados por las partes (en un tribunal colegiado) puedan ser de otras profesiones distintas a la abogacía. 
1 Vigente desde el día siguiente de la publicación de su Reglamento, Decreto Supremo $\mathrm{N}^{\circ}$ 039-98-PCM, es decir, desde el 29 de septiembre de 1998, de conformidad con lo establecido por la Primera Disposición Final de la Ley.

Antes de dicha ley, teníamos el Reglamento Único de Licitaciones y Contratos de Obras Públicas - RULCOP y el Reglamento Único de Adquisiciones - RUA, los cuales disponían procedimientos administrativos y de impugnación judicial (proceso contencioso administrativo). Dichas normas no contemplaban de forma alguna al arbitraje como mecanismo de solución de controversias. Incluso, se hablaba de una dicotomía entre los contratos privados y los contratos administrativos en relación al arbitraje, ya que solo los primeros podían ser sometidos a arbitraje (al respecto, ver Cantuarias Salaverry, Fernando. «Participación del Estado peruano en arbitrajes comerciales». Advocatus. $N^{\circ}$ 7. Lima: Revista editada por alumnos de la Facultad de Derecho de la Universidad de Lima, 2002, pp. 180-181).

2 Cabe recordar que el artículo $63^{\circ}$ de la Constitución Política del Estado contemplaba la posibilidad de que el Estado y las demás personas de derecho público sometieran a arbitraje las controversias derivadas de una relación contractual. Sin embargo, no se establecía la obligatoriedad, como sí lo han hecho y lo hacen las leyes y reglamentos sobre contratación pública.

3 En efecto, entre las ventajas operativas que la doctrina suele destacar en el arbitraje figuran la rapidez y la especialización. En cuanto a la rapidez, pocas dudas puede plantear si se compara hoy en día la duración de un arbitraje con la duración promedio de un proceso judicial. En lo que a la especialización se refiere, hay que tener en cuenta que ello dependerá de que se haya elegido muy bien a los árbitros.

4 Bullard González, Alfredo. «Enemigos íntimos. El arbitraje y los contratos administrativos». Revista peruana de arbitraje. $\mathrm{N}^{\circ}$ 2. Lima: Grijley, 2006, p. 166.

5 Cantuarias Salaverry, Fernando. Ob. Cit., p. 192.

6 Arrarte Arisnabarreta, Ana María y Paniagua Guevara, Carlos. «Apuntes sobre el arbitraje administrativo y la materia arbitrable respecto de adicionales de obra». Advocatus. $\mathrm{N}^{\circ} 16$. Lima: Revista editada por alumnos de la Facultad de Derecho de la Universidad de Lima, 2007, p. 182.

7 Publicado en el Diario Oficial "El Peruano", con fecha 4 de junio de 2008 y entró en vigencia a partir del 1 de febrero de 2009, de conformidad con el artículo 1 del Decreto de Urgencia $\mathrm{N}^{\circ}$ 014-2009, publicado el 31 de enero de 2009. Dicho artículo establecía lo siguiente: «El Decreto Legislativo $\mathrm{N}^{\circ}$ 1017, que aprueba la Ley de Contrataciones del Estado, su Reglamento aprobado por el Decreto Supremo $\mathrm{N}^{\circ} 184-2008$-EF, y el Reglamento de Organización y Funciones del Organismo Supervisor de las Contrataciones del Estado OSCE, cuyo texto fue aprobado por el Decreto Supremo $N^{\circ}$ 006-2009-EF, entrarán en vigencia a partir del 1 de febrero de 2009 [...]».

8 Cabe señalar que el Decreto Ley $N^{\circ} 25935$, antigua Ley de Arbitraje, establecía la posibilidad de obligar a la otra parte a arbitrar, cursándole previamente una carta notarial, en caso de falta de respuesta de la otra parte y sin necesidad de contar con un convenio arbitral. Sin embargo, la anterior Ley de Arbitraje, Ley $\mathrm{N}^{\circ}$ 26572, no dio continuidad a las disposiciones sobre arbitraje obligatorio contenidas en el decreto derogado. (Kundmüller Caminiti, Franz. «Obligatoriedad del arbitraje y otros temas de gestión de conflictos en la Ley de Contrataciones y Adquisiciones del Estado y su Reglamento». Themis. $N^{\circ}$ 39. Lima: Revista editada por alumnos de la Facultad de Derecho de la Pontificia Universidad Católica del Perú, 1999, p. 217).

9 Paredes Carbajal, Gustavo y Gray Chicchón, Jaime. «Mecanismos alternativos de resolución de disputas en construcción». Revista de Derecho Administrativo. № 4. Lima, Círculo de Derecho Administrativo, 2008, p. 205.

10 García-Calderón Moreyra, Gonzalo. «Análisis del arbitraje en la Ley de Contrataciones y Adquisiciones del Estado». Ius et praxis. №32. Lima: Facultad de Derecho y Ciencias Políticas de la Universidad de Lima, 2001, p. 143.

11 García-Calderón hace referencia a la Ley $\mathrm{N}^{\circ} 26572$, ley vigente al momento de la redacción del referido artículo. Sin embargo, cabe precisar que la autonomía de la voluntad de las partes también se encuentra recogida en la actual Ley de Arbitraje, Decreto Legislativo $N^{\circ} 1071$.

12 Baca Oneto, Víctor Sebastián. Los medios "alternativos" de solución de conflictos en el derecho administrativo peruano (en especial, análisis de la transacción y el arbitraje en la Ley de Contratos y Adquisiciones del Estado)». Lima Arbitration. N ${ }^{\circ}$ 1. 2006, p. 232. Disponible en internet: http://www.limaarbitration.net/victor sebastian_baca_oneto.pdf

${ }^{13}$ El citado autor hace la precisión de que la situación es distinta respecto al establecimiento de mecanismos obligatorios de conciliación, pues nada obliga a llegar a un acuerdo y a excluir así el control judicial.

14 Sobre el particular, Donayre se cuestiona por qué el arbitraje es obligatorio en el Perú, si en el resto de países de América Latina es facultativo. Así, cita textualmente las cláusulas arbitrales de las leyes de contrataciones de Colombia, Costa Rica, Guatemala, Honduras, México, Argentina, Bolivia y Nicaragua, en donde el arbitraje sobre temas de contratación pública es potestativo o voluntario, como propone el referido autor para el caso del Perú. 
A entender de Donayre, nada pasa si el arbitraje en obras públicas es optativo y voluntario, como es la filosofía de un mecanismo alternativo de solución de conflictos. No se va a caer el sistema jurídico peruano si es que la Ley de Contrataciones opta por el arbitraje "no obligatorio", por voluntad de las partes (cada Entidad, cada contratista, cada contrato). Donayre Ordinola, Jorge Luis. «Administración, gestión y contratos en obras viales. Riesgos y beneficios de la legislación actual de contrataciones públicas». ADR Resources. Arbitraje y mediación. 2006, p. 9. Disponible en internet: http://www.aryme.com/getdoc.php?section=2\&page=4\&doc_ $\mathrm{id}=32$.

15 Kundmüller Caminiti, Franz. «Exclusión de la sede judicial para la solución de controversias en los contratos del Estado: el arbitraje de derecho». Ius et Praxis. № 34. Lima: Facultad de Derecho y Ciencias Políticas de la Universidad de Lima, 2003, p. 72.

16 Arrarte Arisnabarreta, Ana María y Paniagua Guevara, Carlos. Ob. Cit., p. 181.

17 Citado por Arrarte Arisnabarreta, Ana María y Paniagua Guevara, Carlos. Ob. Cit., p. 185.

18 Arrarte Arisnabarreta, Ana María y Paniagua Guevara, Carlos. Ob. Cit., pp. 185-186.

19 Cuevas Morales, Carlos. «El convenio arbitral en la Ley de Contrataciones y Adquisiciones del Estado». Cathedra. No 8. Lima: Revista de los Estudiantes de Derecho de la Universidad Nacional Mayor de San Marcos, p. 203.

20 Santistevan De Noriega, Jorge. «El arbitraje con el Estado en la nueva Ley Arbitral y en el régimen especial de contratación con el Estado». Actualidad Jurídica. N 177. Lima: Gaceta Jurídica, 2008, p. 27.

${ }^{21}$ Kundmüller Caminiti, Franz. Ob. Cit., p. 74.

${ }_{22}$ Cantuarias Salaverry, Fernando. Ob. Cit., p. 182.

${ }^{23}$ Cabe precisar que el autor hace referencia al Decreto Supremo $\mathrm{N}^{\circ}$ 012-2001-PCM, vigente al momento de la elaboración de su artículo. Sin embargo, sus apreciaciones son plenamente aplicables con la normativa hoy vigente.

${ }^{24}$ García-Calderón Moreyra, Gonzalo. Ob. Cit., pp. 144.

25 Ibídem.

${ }^{26}$ Kundmüller Caminiti, Franz. «Obligatoriedad del arbitraje y otros temas de gestión de conflictos en la Ley de Contrataciones y Adquisiciones del Estado y su Reglamento». I us Et Praxis. N 34. Lima: Facultad de Derecho y Ciencias Políticas de la Universidad de Lima, 2003, pp. 217-218.

27 Fernando de Trazegnies menciona que el arbitraje de conciencia goza - muchas veces - del favor de los hombres de negocios porque estos desconfían del formalismo frecuentemente excesivo del derecho oficial. Acostumbrados a cerrar contratos fundamentalmente sobre la base de la buena fe, quieren que la solución de los conflictos que se originan de ellos, se encuentre basada también en la buena fe antes que en una interpretación literal de un texto normativo.

Otras veces, se escoge el arbitraje de conciencia porque el problema excede el ámbito de las leyes nacionales. En estas condiciones, para evitar tener que fijar una ley nacional que gobierna el contrato entre las varias posibles, se opta por un arbitraje de conciencia que permite al árbitro usar varias leyes nacionales a la vez desde la perspectiva de lo que fue la común intención de las partes.

También se opta por un arbitraje de conciencia cuando la controversia tiene aspectos técnicos tan complejos que las normas generales del derecho de obligaciones no aportan todos los elementos necesarios para comprender cabalmente la discusión. (De Trazegnies Granda, Fernando. «Arbitraje de derecho y arbitraje de conciencia». Ius et Veritas. Lima: Revista editada por alumnos de la Facultad de Derecho de la Pontificia Universidad Católica del Perú, 1996, №12, p. 116).

28 Aliaga Grez, Álvaro. Los recursos procesales en el juicio arbitraje. Santiago de Chile: Editorial Jurídica de Chile, 1985, pp. 17-21.

29 De Trazegnies Granda, Fernando. Ob. Cit., p. 116.

30 Citado por Cantuarias Salaverry, Fernando y Aramburú Yzaga, Manuel Diego. El Arbitraje en el Perú: desarrollo actual y perspectivas de futuro. Lima: Fundación M. J. Bustamante de la Fuente, 1994, p. 365.

31 Publicada en el Diario Oficial "El Peruano" con fecha 10 de diciembre de 1992. Cabe señalar que dicha ley fue la primera norma especial sobre la materia en el Perú, la misma que estuvo inspirada en la Ley Española de Arbitraje de 1988.

32 Cantuarias Salaverry, Fernando y Aramburú Yzaga, Manuel Diego. Ob. Cit., p. 262.

${ }^{33}$ Zegarra Pinto, José. «Arbitraje de conciencia: ¿Género del arbitraje de derecho?». Arbitraje on Line. Lima: Centro de Conciliación y Arbitraje Nacional e Internacional de la Cámara de Comercio de Lima, 2005, Año III, $\mathrm{N}^{\circ}$ 5, p. 2.

${ }^{34} \mathrm{El}$ autor señala que, en el caso de Latinoamérica, dicha opción legislativa es compartida por países como Colombia, Costa Rica, México y Venezuela, entre otros.

35 Kundmüller Caminiti, Franz. «Obligatoriedad del arbitraje y ...», p. 218.

${ }^{36}$ García-Calderón Moreyra, Gonzalo. Ob. Cit., p. 148. 